Association for Information Systems

AIS Electronic Library (AISeL)

UK Academy for Information Systems

Conference Proceedings 2016

UK Academy for Information Systems

Spring 4-12-2016

\title{
DURATION OF COMPETITIVE ADVANTAGE DUE TO EMERGING TECHNOLOGY ADOPTION (22)
}

Theophanis Stratopoulos

University of Waterloo, tstratopoulos@uwaterloo.ca

Follow this and additional works at: https://aisel.aisnet.org/ukais2016

\section{Recommended Citation}

Stratopoulos, Theophanis, "DURATION OF COMPETITIVE ADVANTAGE DUE TO EMERGING TECHNOLOGY ADOPTION (22)" (2016). UK Academy for Information Systems Conference Proceedings 2016. 41.

https://aisel.aisnet.org/ukais2016/41

This material is brought to you by the UK Academy for Information Systems at AIS Electronic Library (AISeL). It has been accepted for inclusion in UK Academy for Information Systems Conference Proceedings 2016 by an authorized administrator of AIS Electronic Library (AISeL). For more information, please contact elibrary@aisnet.org. 


\title{
DURATION OF COMPETITIVE ADVANTAGE DUE TO EMERGING TECHNOLOGY ADOPTION
}

\author{
By \\ Theophanis C. Stratopoulos \\ tstratopoulos@uwaterloo.ca \\ University of Waterloo
}

\begin{abstract}
The objective of this study is to provide a framework for predicting the expected duration of a competitive advantage due to adoption of an emerging technology, and suggest a process for generating technology specific benchmark of expected duration for the average adopting firm. Our framework integrates elements from the technology adoption (diffusion) cycle, hype cycles of emerging technologies, and the resource based view conceptualization of number of firms associated with a perfectly competitive market equilibrium. The objective of this synthesis is to generate a framework for estimating average technology diffusion time and standard deviation. Given the prevailing assumption that technology diffusion follows an approximate bell shaped distribution, we can use these two values to estimate the duration of a technology adoption related competitive advantage. We demonstrate the empirical estimation of expected duration of competitive advantage for an emerging technology (cloud computing) and a mature one $(E R P)$.
\end{abstract}

Keywords: Technology adoption, competitive advantage, duration, RBV, hype cycle

\section{Introduction}

Data analytics, big data, cloud computing, and internet of things are just a few of the recent technological innovations. A total of 236 emerging technologies were identified by Gartner Inc., over the period 2003 to 2015. The rate of adoption of new technologies has significant implications for adopting firms, suppliers of these technologies, and investors. Some of these technologies have the potential to disrupt the competitive landscape and provide adopting firms a competitive advantage. The objective of this study is to provide a framework for predicting the expected duration of competitive advantage due to adoption of an emerging technology, and suggest a process for generating technology specific predictions of expected duration for the average firm. 
This study builds on prior literature on technology adoption/diffusion and the resource based view. The early literature on diffusion of innovations, i.e., the process by which an innovation spreads across a population of adopters, is based on the work of Rogers (1995). ${ }^{1}$ In his original work, Rogers approaches diffusion as a decision driven by pursuit of efficiency or profitability. Rogers examined a population of potential adopters to determine the rate and pattern of adoption, as well as characteristics of the emerging technology and its adopters. Rogers' original approach - which is also known as the economic-rationalistic approach (Cyert and March 1992) - was criticized for its proinnovation bias. Several subsequent studies focused on fad/fashion based diffusion (Abrahamson 1991; Abrahamson and Rosenkopf 1993), i.e., adoption that is driven by the number and reputation of previous adopters (Meyer and Rowan 1977; DiMaggio and Powell 1983). The Gartner Hype Cycle (Gartner n.d.), which originated from the professional community, combines elements of hype (fad/fashion) driven early adoption with subsequent post-hype rational adoption to capture the diffusion of emerging technologies in business applications. While the role of a firm as a technology adopting entity is central in this literature, the expected duration of technology adoption related competitive advantage is at best tangentially addressed.

In strategic management literature, the resource based view (RBV) theorizes that the source of a firm's competitive advantage lies in its resources and capabilities (Wernerfelt 1984; Penrose 1995). If a firm possesses resources which are valuable and heterogeneously distributed among competing firms, the firm would have a sustained competitive advantage (Barney 1991; Dierickx and Cool 1989). The work of Mata et al. (1995) introduced the resource based view in the context of the business value of information technology (IT) literature, and provided the theoretical foundation of empirical studies on sustainability of IT related competitive advantage. For example, Dehning and Stratopoulos (2003) found that managerial IT skills are positively related to the sustainability of competitive advantage due to IT enabled strategies. Lim et al. (2011) examined firms that have been recognized for their IT innovation capability, and found that IT innovation capability is path dependent, hence a source of sustainable competitive

${ }^{1}$ The original work was published in 1962. 
advantage. However, studies with an explicit focus on payoffs due to adoption of emerging technologies or capabilities associated with the adoption of these technologies, either do not use on RBV to justify the duration advantage that they test (e.g., Hendricks et al. 2007) or do not test the duration of competitive advantage (e.g., Zhu 2004).

In this study, we propose a synthesis/mapping of the technology adoption (diffusion) cycle (Rogers 1995), the hype cycles of emerging technologies (Gartner n.d.), and the resource based view conceptualization of number of firms associated with a perfectly competitive market equilibrium (Lim et al. 2011; Barney 2002; Amit and Schoemaker 1993). The objective of this mapping/synthesis is to generate a framework for estimating the average technology diffusion time and standard deviation. Given the prevailing assumption that technology diffusion follows an approximate bell shaped distribution (Rogers 1995), we can use these two values - in conjunction with RBV - to estimate the duration of a technology adoption related competitive advantage. ${ }^{2}$ While the duration of competitive advantage will vary across firms due to a host of firm specific factors, such as the firm's business strategy, innovation culture, organizational capabilities, and investments in complementary resources, our objective is to estimate the competitive advantage for the average adopting firm.

The main challenge is that of making predictions soon enough to make them useful versus waiting until more evidence has been collected in order to make them more accurate. This tradeoff is captured in the first set of our propositions (1a and 1b). The former, with a focus on generating early predictions; proposes that observing two stages of the hype cycle lets us predict one standard deviation of adoption time. The latter, with a focus on accuracy, proposes that we have to wait until four stages of the hype cycle have been observed to estimate two standard deviations of adoption time. The adoption rate of an emerging technology is likely change dramatically due to certain events - e.g., the development of a complementary or competing technology, regulatory changes, or changes in market conditions. With our second proposition, we recognize this possibility and propose that observing the first two stages of the hype cycle lets us predict two,

\footnotetext{
${ }^{2}$ A normal distribution can be fully specified by its mean and standard deviation
} 
rather than one, standard deviations in the adoption cycle. With our third proposition, we postulate that competitive benefits become asymptotically zero by the time the new technology has reached three standard deviations in the adoption cycle, i.e., the approximate center of the adoption cycle.

We demonstrate the empirical estimation of expected duration of competitive advantage for two technologies (cloud computing and ERP). For cloud computing estimation, we use three sources (proxy for expectations): Google Trends to capture web search interest, LexisNexis to capture news stories with focus in cloud computing, and Gartner Hype Cycles for emerging technologies. All three sources produce comparable results. For ERP, we rely on prior literature to show that our predictions are consistent with evidence from empirical studies.

The mapping/synthesis based framework and proposed methodology are not without limitations. Relying on hype cycle to generate predictions may lead to false estimates. In our discussion we present two examples: The first one shows that our methodology will not work when dealing with an emerging technology, such as cryptocurrency, which goes through multiple hype cycles. The second one, builds on the fact that theoretically a bell shaped distribution has no limits. Which means that selection of commencement of the new technology will affect the prediction. We demonstrate this by examining the hype cycle of customer relationship management (CRM) systems. Depending on the chosen commencement year of CRM one would arrive at dramatically different results.

The study contributes to two major and distinct streams of literature (technology diffusion and resource based view) by providing a mapping/synthesis based framework and a relatively simple way to implement the derived propositions. The implementation could be useful to researchers interested in technology adoption and IT business value, in order to generate an initial benchmark of the expected duration due to technology adoption. For example, Hendricks et al. $(2007,70)$ state that:

“... The existing literature provides little guidance on what should be the appropriate length of the post-implementation period over which one should measure the benefit of investments in ES. There does seem to be an agreement that 
the benefits will be felt over a long time period. Given this, we choose a three-year post-implementation period for ERP, SCM, and CRM applications. Overall, we examine the changes in financial performance over a five-year period for ERP systems (a two-year implementation period and a three-year post-implementation period), and a four year period for SCM and CRM systems (a one-year implementation period and a three-year post-implementation period)."

This benchmark can be used to gauge the incremental effect of firm specific attributes, such as IT capability and management skills, on a firm's ability to sustain its technology adoption related competitive advantage.

The study has practical implications. First, it would be useful for mindful adopters of technological innovations (Swanson and Ramiller 2004) and firms that have developed a sustained reputation for their IT innovation capability (Stratopoulos and Lim 2010; Lim et al. 2011) to select investments in emerging technologies that could provide the maximum contribution to their existing competitive advantage. Second, generating predictions regarding the expected duration of competitive advantage could be useful to financial managers trying to estimate the net present value of an investment in an emerging technology. The estimated duration could be used to discount net cash flows associated with this investment. Third, the same estimation could be useful for investors and analysts trying to value the market reaction to a firm's decision to adopt the new technology. The estimated duration would be used to discount future earnings. Finally, it would be useful to the top management teams of firms supplying the new technology, as it would allow them to calibrate their strategy for the growth and maturity stage of their product's life cycle.

\section{Background and Synthesis}

\subsection{Technology adoption theory}

According to Rogers (1995) adoption of a new technology by individuals or firms tends to follow an approximate bell shaped distribution (See Figure 1). Rogers (1995) argues that adoption of new technologies follows the bell shaped distribution because of the cumulative influence upon potential adopters from peer networks. In business terms, this means that the documented profitability and efficiency gains of firms that were the first 
to adopt would force non-adopters to either follow in order to catch up or be in a position of competitive disadvantage. Using the properties of the bell shaped distribution (empirical rule), Rogers (1995) proposed the following five categories of technology adopters: $:^{3}$

Innovators are the first to adopt a new technology. The adoption of the new technology is associated with a high level of uncertainty for two reasons. First, the technology is at the experimental stage, which means that its functionality may not have been fully developed. Second, it is quite possible that adopters may not have a clear picture of how to integrate the new technology with their existing processes, and more importantly, the expected benefits may not be clear. Therefore, the advantage of making such an investment ahead of the vast majority of competitors is balanced by the high risk that the investment may fail to deliver positive and significant payoffs. In general, innovators are firms with a high appetite for risk and strong financial position. The latter enables them to afford potential losses associated with high risk projects.

The second group, early adopters, though not as risk seeking as the innovators, still have to deal with relatively high levels of uncertainty. The technology is not at the experimental stage anymore, but this does not mean that it has reached technological maturity. Typically, early adopters have been able to observe and learn from the successes and failures of innovators. They can leverage this experience to manage the risk associated with implementation of the new technology and increase the likelihood of successful business assimilation. The role of early adopters is pivotal: their success will trigger mass adoption (early majority), while their failure means the end of the new technology. The early Majority will join the adoption process at the stage when the risks have been mitigated, but while the benefits of the adoption are still relatively high. Collectively these three groups represent approximately $50 \%$ of potential adopters.

\footnotetext{
${ }^{3}$ Obviously the classification is only applicable in the case for successful technological innovations. There are many innovations that fail to go beyond the innovator or early innovator stage.
} 


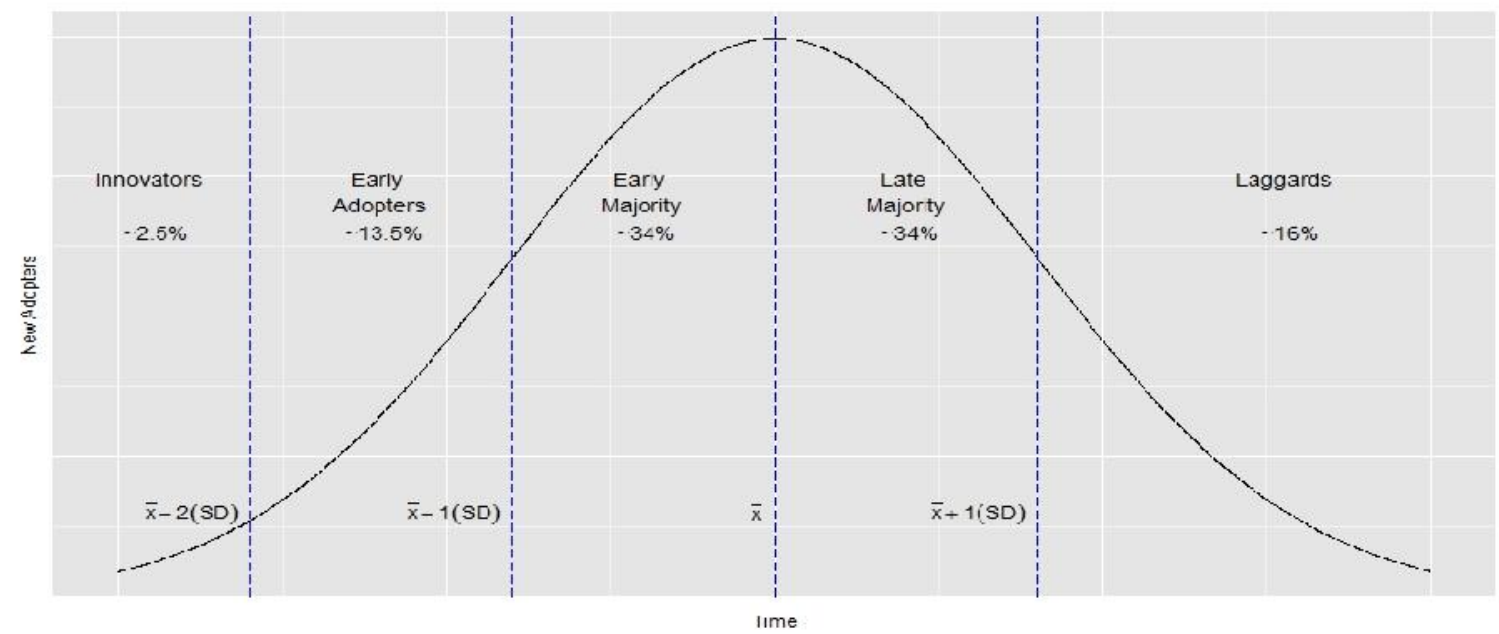

Figure 1: Rogers Innovation Adoption Cycle

The last two groups - late majority and laggards- represent the remaining 50\%. The former reflects adopters that invest in the new technology as a result of strong peer pressure. From a business standpoint, this means that the late majority adopters have already realized that its peers have gained a competitive advantage, and investment in the new technology is a necessity if they want to catch up with their competitors. There are several reasons why laggards are the last to adopt. The role of the new technology in their operations may be tangential, they may simply be hostile to new technologies, or very conservative in the way they think and operate.

Obviously, the mean and standard deviation needed to specify the exact shape of an adoption cycle are specific to each new technology. To acquire the additional specificity needed, in the following section, we turn our attention to the Hype Cycle.

\subsection{Technology life cycle (Gartner Hype Cycle)}

The Hype Cycle was developed by Gartner, a technology consulting company, and is defined as follows (Gartner n.d.): ... A Hype Cycle is a graphic representation of the maturity, adoption and business application of specific technologies. 


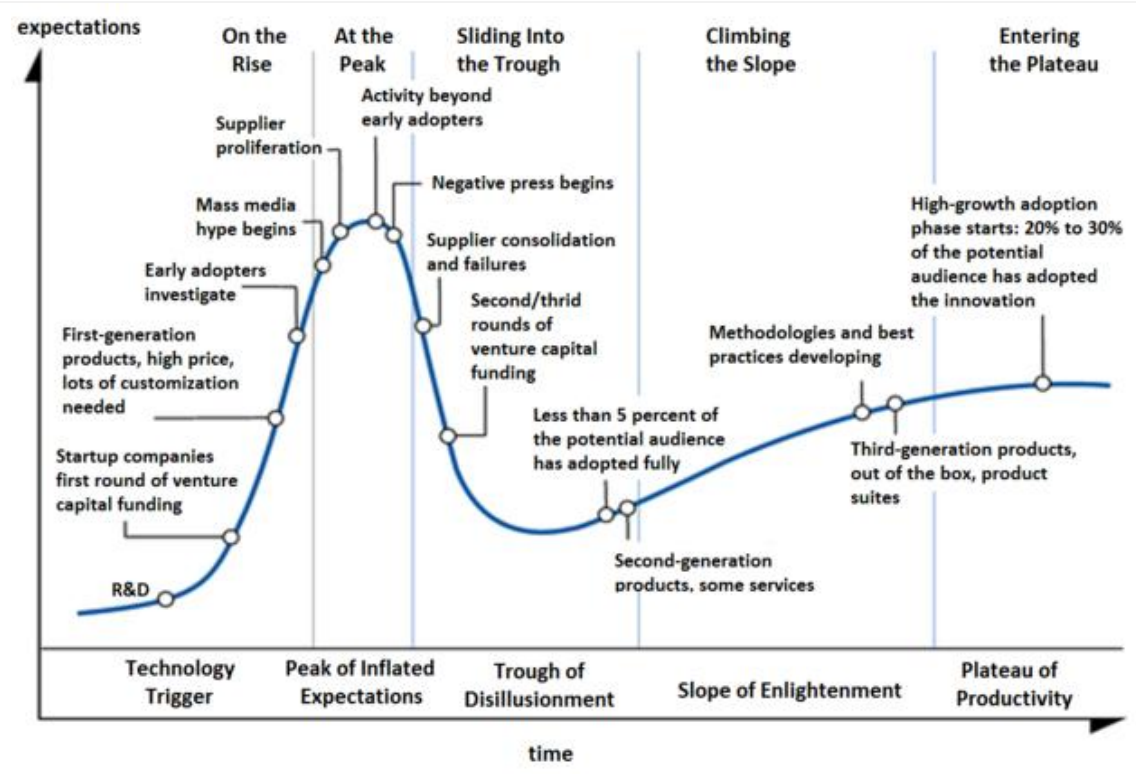

Figure 2: Gartner Hype Cycle (Source: Wikipedia)

According to Gartner, the life cycle of nascent technologies goes through the following five stages (Figure 2): The emerging technology starts with a technological breakthrough or a proof-of-concept, which triggers public interest in the new technology (Innovation Trigger). The new technology is still at the experimental stage and no viable business applications have been developed yet. Typically, the innovation trigger is followed by increased publicity. Dramatized success stories of selected adopters tend to ignore the technology's technical limitations and exaggerates the potential benefits. The technology enters the period of unrealistic expectations (Peak of Inflated Expectations). Some of the innovators adopting the technology at this stage are motivated by fad and have unrealistic expectations.

Given that the technology is at an exploratory stage with no explicit and proven way to monetize it, the majority of first generation adopters fail to extract value from their investment and the initial hype is followed by the Trough of Disillusionment. While, some of the developers and adopters exit, a hard core group continues trying to improve the technology and figure out ways of extracting value from the new technology. Overall adoption remains at less than 5\%. Gradually, new instances of how the new technology can deliver tangible benefits emerge, renewing the interest and spawning a new 
generation of adopters (Slope of Enlightenment). Their success provides proof that the technology is viable and generates benefits, thus mainstream adoption takes off (Plateau of Productivity).

Position of an emerging technology to a specific stage in the Gartner Hype Cycle is not based on hard evidence or scientific analysis. It simply represents the perceptions of Gartner analysts. Given the focus of the hype cycle on business applications (i.e., the plateau of productivity), each technology showing in the annual hype cycle of emerging technologies is accompanied with an estimate regarding the number of years it would take for the technology to reach the plateau of productivity.

While the hype cycle provides estimates regarding the time it would take for an emerging technology to reach the plateau of productivity, it does not provide the additional information needed to establish the expected duration of competitive advantage due to adoption. In the following section, we introduce the resource based view in order to complete the last piece of the proposed mapping/synthesis framework.

\subsection{Technology adoption and competitive advantage}

From a strategic management standpoint, firms adopt emerging technologies in an attempt to improve or simply sustain their competitive position. Ceteris paribus, if all firms competing in a market have access to the same technology, they are likely to be in competitive parity. Access to a technology that would allow one of these firms to perform different activities than its competitors or perform the same activities at a lower cost would give this firm a competitive advantage. This is the main premise behind RBV, i.e., the distribution of resources and capabilities among competing firms is a key determinant of a firm's relative performance. Only resources and capabilities, which are valuable and heterogeneously distributed among competing firms, are a source of competitive advantage. The more persistent the heterogeneity, the longer the duration of a competitive advantage. More specifically, we can assess the implications of adoption of an emerging technology on a firm's competitive position using the (Mata et al. 1995) RBV framework (Figure 3). 
Typically, a firm would adopt a new technology expecting that this would increase its value (i.e., the expected net present value of the technology adoption is positive). However, the adoption of an emerging technology is risky and it may generate negative expected payoffs. For example, the firm may fail to implement successfully, the technology may not be stable, or the firm may not be able to assimilate the new technology. If we assume that all firms were originally in a position of competitive parity, the investment in a technology that is not valuable is likely to put the adopting firm in a position of relative disadvantage. However, if the technology is valuable, the question becomes: Is it heterogeneously distributed among competing firms?

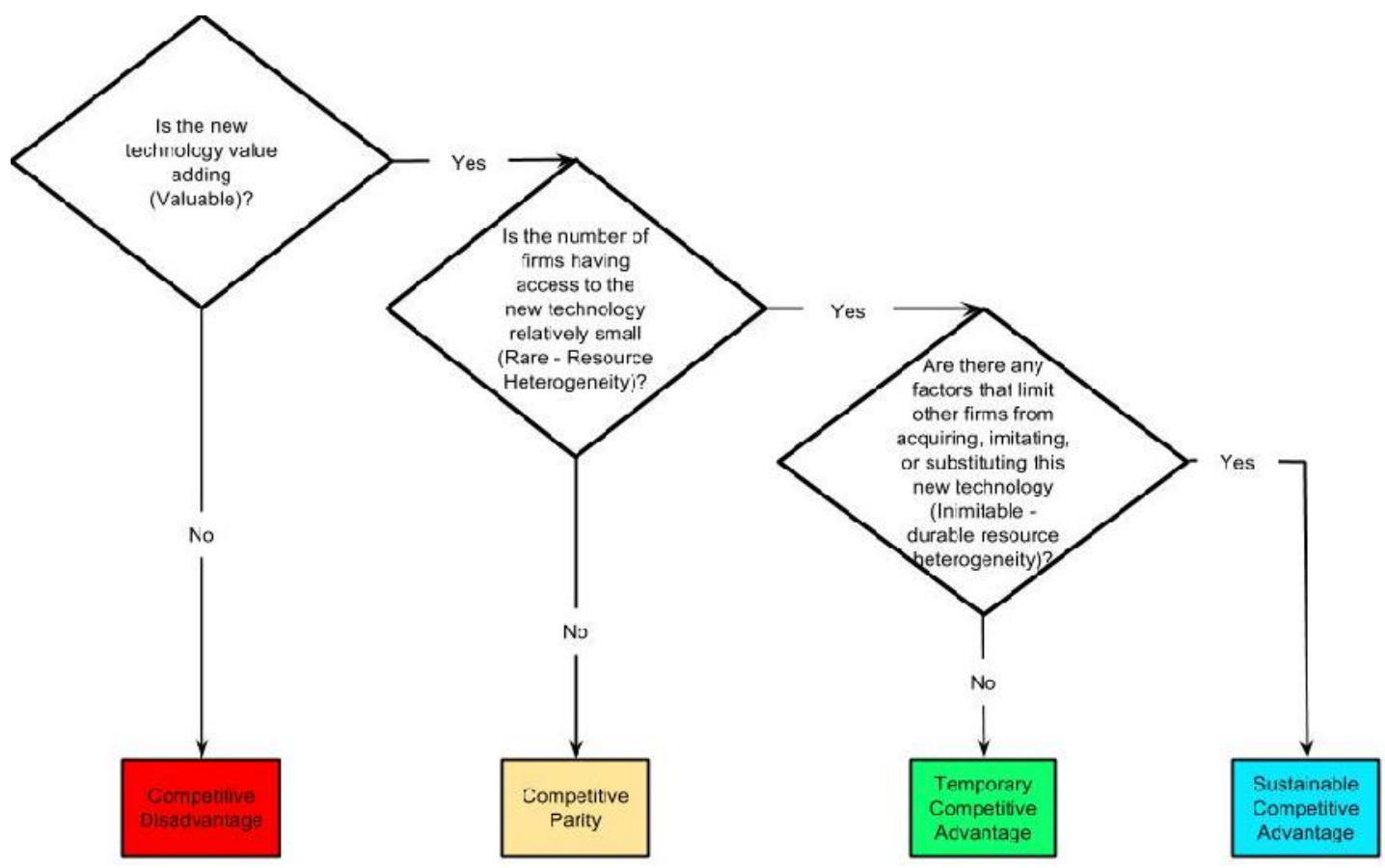

Figure 3: Resource Based View Framework

The heterogeneity of a new technology among potential adopters would depend on host of technology and firm specific factors. For example, if a supplier can readily provide stable version of the new technology to all potential adopters at a relatively low cost, the technology would be valuable but not heterogeneous. The diffusion of the new technology would be rapid among all firms in this market and adopters would simply 
maintain their competitive parity. However, it is highly unlikely that a supplier would achieve this level of maturity instantly and/or adopting firms would have access to all resources and capabilities needed to successfully adopt and assimilate the new technology. Therefore, the next issue becomes that of duration of heterogeneity. If the heterogeneity is quickly dissipating the adopting firm will enjoy only a temporary competitive advantage. Else, the advantage is sustainable.

According to the resource based view, there are several factors that could affect the duration of heterogeneity. Adopting firms can leverage a combination of technology specific attributes with firm specific resources and capabilities to raise barriers to imitation or isolating mechanisms. ${ }^{4}$ Causal ambiguity and path dependence are two such isolating mechanisms. The former refers to fact that imitators would have to understand the way that the new technology has been assimilated and how it contributes to a competitor's advantage before they can replicate it. The later reflects the importance of choices made during the early stages of a project that have significant implications on current choices, decisions, and expected outcomes. This means that in order to arrive to the current status of a competitor's competitive position, its peers will have to take the same path the competitor has taken. Therefore, the stronger the causal ambiguity and/or path dependence the longer the duration of heterogeneity.

Based on the above we conclude that the number of firms that have access to a resource, and the time it takes for firms that have no access to this resource to acquire it are the two proxies for relative competitive value of the resource. The role of the number of firms can be understood by drawing on microeconomic theory. In the extreme case that only one firm has access to a resource, the owner will behave as a virtual monopolist and extract the maximum level of economic profits. The monopolist has a competitive advantage. The other extreme is that of perfect competition - all firms in the market have access to the same resource and none of them earns economic profits. Therefore, when the number of firms that has access to this resource reaches a perfectly competitive

\footnotetext{
${ }^{4}$ See Dehning and Stratopoulos (2003) for a list of barriers to imitation and isolating mechanisms.
} 
equilibrium, adoption is valuable but it does not yield competitive payoffs for its adopters. If the number of firms that possess a resource or capability is relatively small (less than the number of firms needed to generate perfectly competitive equilibrium in a market), the resource or capability is rare and a potential source of competitive advantage. In addition, if competitors find it difficult to acquire, substitute, or imitate these resources/capabilities, then these firms enjoy a competitive advantage. If the number of firms that have access to a resource is small, and remains small for a relatively long time, these firms will enjoy a sustainable competitive advantage (Figure 4 - left panel). Else, the advantage is temporary (Figure 4 - right panel).
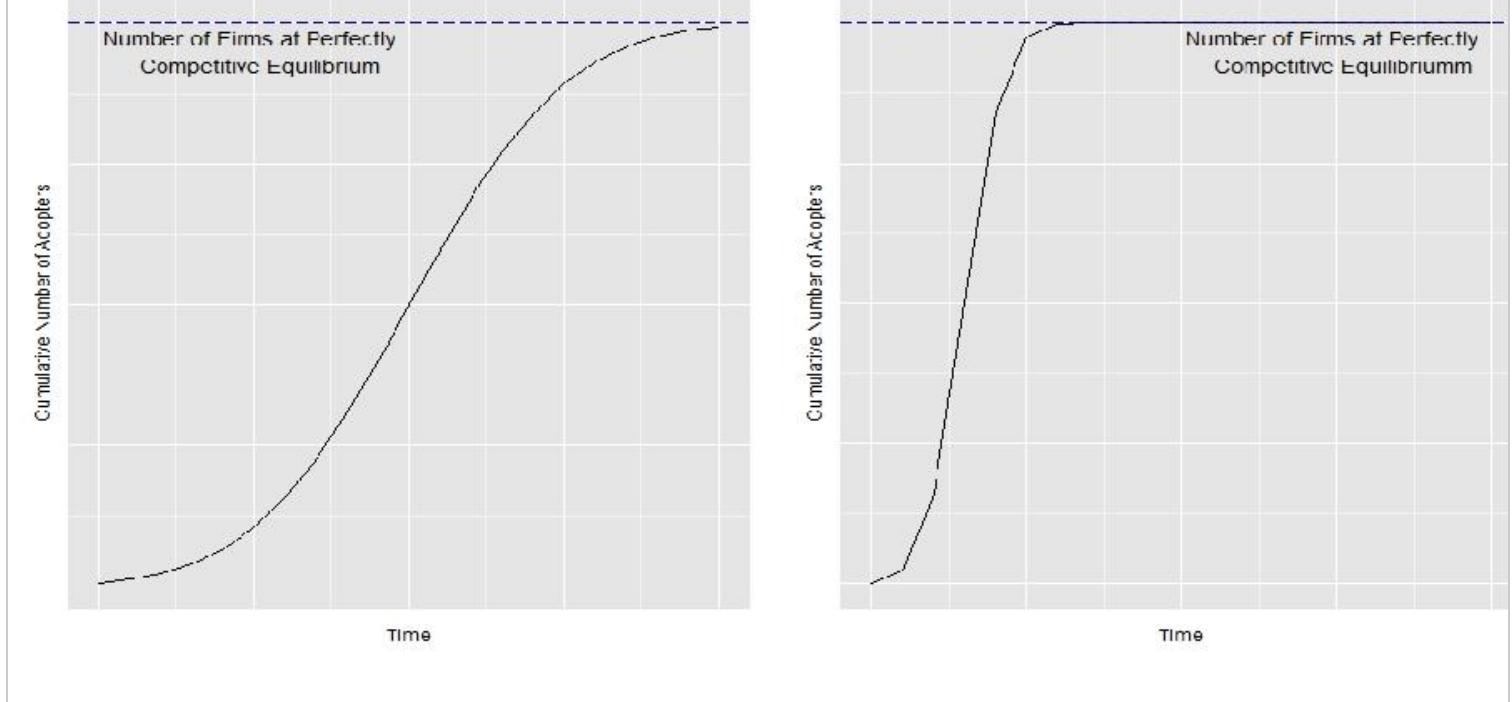

Figure 4: Number of Firms at Perfectly Competitive Equilibrium

\subsection{Synthesis - propositions}

In order to generate predictions regarding the expected duration of the competitive advantage for the average adopting firm; we need to specify the expected mean and standard deviation of the technology related adoption cycle, and establish an approximate adoption threshold that could be associated with no competitive advantage. In the following paragraphs, we will propose a mapping between the adoption cycle and hype cycle of an emerging technology in order to identify the two parameters (mean and 
standard deviation), and leverage resource based view to establish the threshold of no competitive gains.

Proposition 1a: According to the adoption cycle, innovators are willing to adopt the new technology while still at the experimental stage. From the description of the hype cycle, we know that the new technology remains at the experimental stage during the innovation trigger stage and peak of inflated expectations. Given that the innovator's adoption period reflects approximately one standard deviation in the adoption cycle, we propose that the time from the introduction of the new technology until the end of the peak of inflated expectations reflects approximately one standard deviation (Figure 4).

Proposition $1 b$ : While innovators are willing to take high risk, early adopters will not adopt until some of the technological uncertainty and business related uncertainty has been removed. Both of these kinds of uncertainty will start being mitigated as the technology goes through the trough of disillusionment and the slope of enlightenment. Therefore, innovators and early adopters are likely to adopt the new technology up to the late stages of the slope of enlightenment. This provides the foundation for proposition $1 \mathrm{~b}$, i.e., that the period from the introduction of the new technology up to the late stages of the slope of enlightenment reflects a period of approximately two standard deviations in the adoption cycle.

Proposition 2: The adoption rate is likely to change due to several technological and economic factors. For example, the adoption of technology A is likely to slow down, if there is a new technology B that performs better than A. On the other hand the adoption of $\mathrm{A}$ is likely to accelerate, if it can serve as the foundation (prerequisite) for the adoption of a new lucrative technology $\mathrm{C}$. Adoption rate is likely to accelerate when the technology is hitched to an economic bubble and/or bandwagon effect. To account for this possibility, we propose that in cases that adoption is related to such factors, the first two stages of the hype cycle lets us predict two, rather than one, standard deviations in the adoption cycle. 

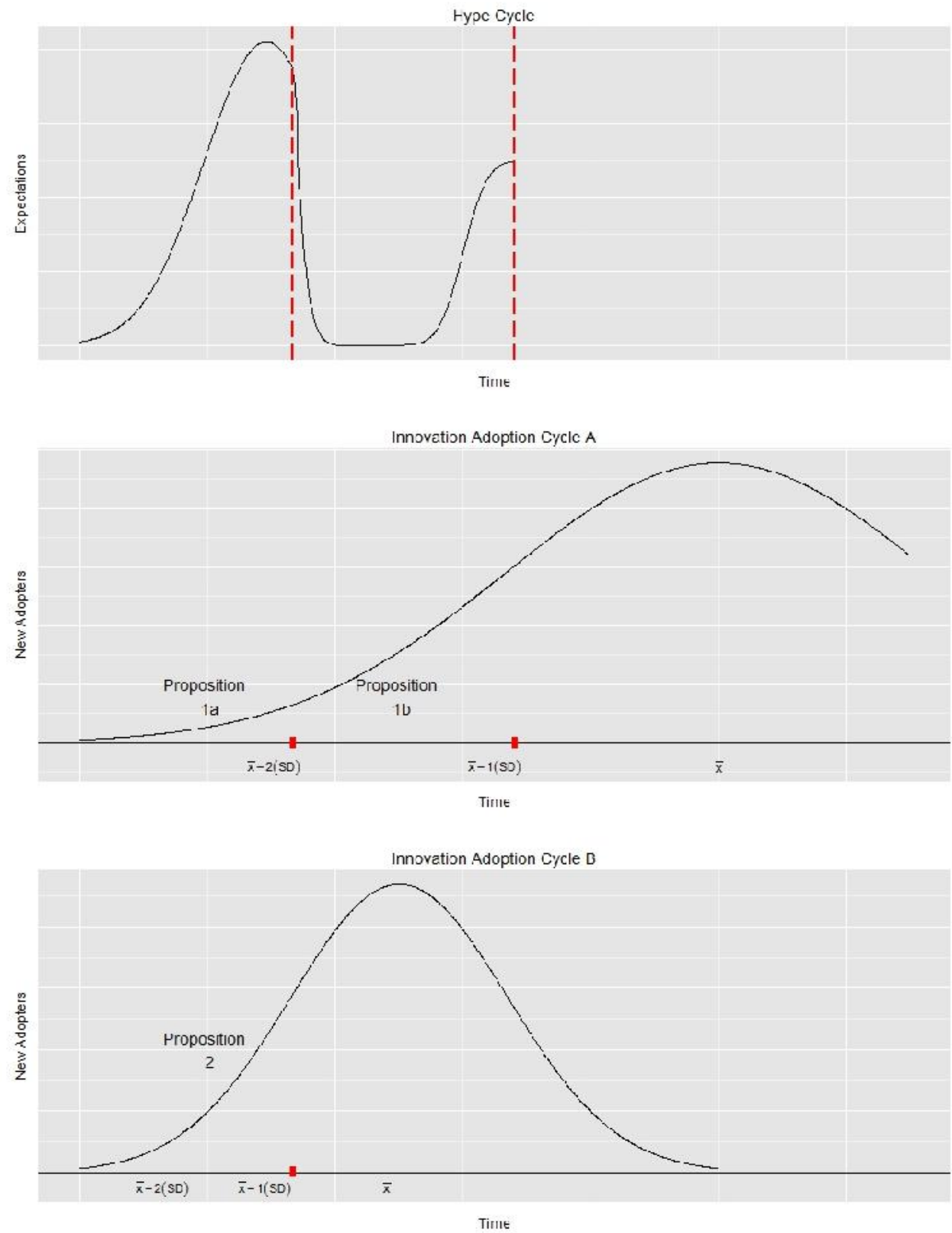

Figure 5: Propositions

Proposition 3: The targeted population of potential adopters is comprised of firms, which are expecting that adoption would generate a positive net present value. The relative expected benefits (competitive advantage) would depend on how many firms have already adopted the technology. The competitive advantage will asymptotically approach zero as the number of adopting firms is approaching the number of firms in a perfectly 
competitive market. According to adoption cycle, late majority would adopt the new technology because of strong competitive pressure. This means that the competitive benefits will start getting smaller (economic profits will start approaching zero) by the end of the early majority. Therefore, the number of technology adopting firms will approach the number of firms in a perfectly competitive equilibrium by the time that late majority of adopting firms has started adopting the new technology, i.e., the average (mean) time of the adoption cycle.

\section{Methodology an Estimation Process}

The main premise behind an attempt to estimate the duration of an emerging technology adoption related competitive advantage is that of establishing whether the emerging technology would diffuse rapidly or slowly. According to Rogers (1995) there are several factors that would affect the shape of technology adoption. Arguably, the most significant factor is potential adopter's expectations regarding the value adding contribution. The higher the perceived advantage by potential adopters, the faster will be the adoption rate. Other factors include the perceived compatible with potential adopters' needs, level of complexity in implementation of the new technology, ability to experiment with the new technology, and information or evidence regarding the implementation obstacles or factors that lead to higher success from existing adopters. ${ }^{5}$ Our goal is not to examine such attributes, but try to introduce some proxy that would capture the expected adoption cycle.

Given that the main underlying variable that changes over time and thus determines diffusion rate is potential innovators' assessment of future expected value, we follow the suggestion of Fenn and Raskino (2008) and use the number of articles in newspapers and magazines as a proxy for measuring expectations. In the following sections we explore the use of Google Trends and LexisNexis to generate a proxy for expected value.

\footnotetext{
${ }^{5}$ There is an extensive literature that has looked at the attributes of emerging technologies that make some technologies more attractive and diffuse more rapidly than others. For a review of this literature see Fichman (2000).
} 


\subsection{Predictive analysis: Google Trends \& LexisNexis}

Google Trends is a public service offered by Google that shows how often a specific search-term has been used relative to the total search-volume by geographic region and over time. The results are shown in a graph or tabulated. In the graph the horizontal axis represents time (starting from 2004), and the vertical axis is the relative popularity of the search term in a given geographic region and time frame. ${ }^{6}$ One would expect that the search interest would be positively correlated with the expected value of the emerging technology. In the following paragraphs, we would focus on one emerging technology (cloud computing) and limit our search interest in one geographic region (United States).
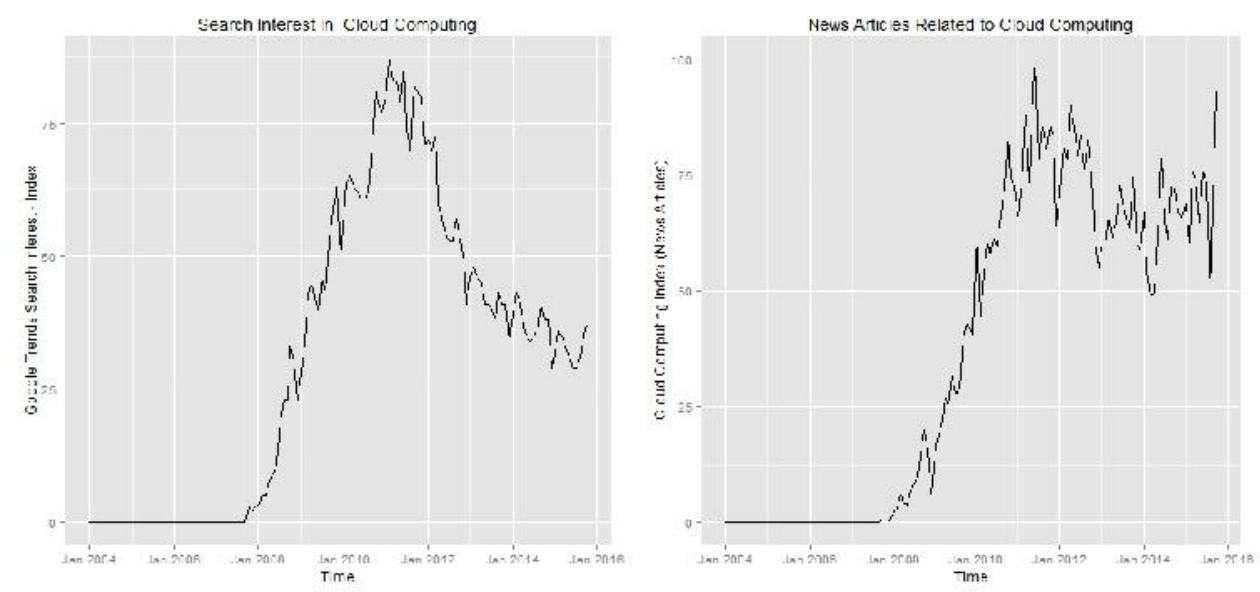

Figure 6: Cloud Computing: Google Trends (left) and LexisNexis (right)

Cloud Computing has been described as the delivery of computing as a service rather than a product. It enables on demand access to a shared pool of configurable computing resources such as network servers, data storage, and software applications. ${ }^{7}$ Software as a

\footnotetext{
${ }^{6}$ According to Google Trends, "Numbers represent search interest relative to the highest point on the chart. If at most $10 \%$ of searches for the given region and time frame were for 'pizza,' we'd consider this 100. This doesn't convey absolute search volume."

${ }^{7}$ Mell P, Grance T. 2011. The NIST Definition of Cloud Computing. Recommendations of the National Institute of Standards and Technology. Special Publication, National Institute of Standards and Technology - U.S. Department of Commerce, Gaithersburg, MD: 7. Available at: http://csrc.nist.gov/publications/nistpubs/800-145/SP800-145.pdf. Key words related to cloud computing
} 
service (SaaS) has been around since the late nineties. However, the more recent version of cloud computing - i.e., one that includes Platform as a Service (PaaS). Infrastructure as a Service (IaaS) - was 'formally' introduced with Amazon's introduction of Elastic Compute Cloud in August of 2006 (Hof 2006).

For the generation of expectation proxy, we have used Google trends and the keyword "cloud computing." 8 The Google Trends results (Figure 6 - left pane) show that, while cloud computing was introduced in the summer of 2006, the public started being interested in this in the fall of 2007. Interest has been rising in the following years, reaching its peak in 2011 and starting to decline by the end of the same year. Based on this, we estimate that the innovation trigger and peak of inflated expectations lasted from 2006 to 2011.

Therefore, according to proposition 1a, we estimate that the standard deviation of the technology adoption cycle of cloud computing is approximately 5 years. Observing the Google trend in the remaining years, we see that it has entered into the trough of disillusionment in 2012 and kept declining in 2013, showing some signs of stability in 2014. Therefore, we can postulate that it may have been transitioning from trough to slope of enlightenment in 2014 and 2015. Unfortunately, the evidence is not adequate to apply proposition $1 \mathrm{~b}$, and establish a second point of reference/generate some additional evidence regarding the standard deviation of the adoption cycle of cloud computing.

The number of news stories has been suggested as another proxy for the future expected value of an emerging technology (Fenn and Raskino (2008)). We used LexisNexis and focused our search to news stories where some variation of the term "cloud computing" appeared in the headline, highlights, lead paragraph or abstract of a story. To maintain consistency with Google Trend, we specified the same geographic region (USA) and

service models: Software as a Service (SaaS). Platform as a Service (PaaS). Infrastructure as a Service (IaaS).

${ }^{8}$ The addition of terms such as IaaS, Infrastructure as a Service, PaaS, and Platform as a Service did not produce a significant volume of search results to alter the overall results. I have removed these terms from the analysis to simplify the analysis and graph. 
same time period (2004-2015). Following the same approach as the one used by Google Trends, we created an index of news articles (i.e., report count as percentage of max value). The results shown in Figure 6 (right panel) show a similar pattern to the one from Google Trends, i.e., the number of new stories peaked in 2011.

For additional support, we turn into the Garner generated hype cycles over this period. Analyzing hype cycles from 2004 to 2015 we find the following: Cloud computing appears as an emerging technology in 2008 and remains in the hype cycles until 2014. Over these years it has the following classification: 2008 on the innovation trigger, 20092011 at the peak of expectations, and 2012-2014 into the trough of disillusionment. Cloud computing has been removed from the Gartner's 2015 hype cycle of emerging technologies and has been replaced with "Hybrid cloud computing", which remains classified in the trough. Overall, the results of the Gartner hype cycles are consistent with our findings from Google Trends and LexisNexis. Based on the above, we estimate that the cloud computing would reach its $50 \%$ cumulative adoption rate by the early 2020 s. Summary results in Table 1, show that it would cease producing relative competitive benefits for its adopters after the early 2020s.

While the triangulation of cloud computing results provides some comfort these predictions cannot be currently verified. In addition to this; adoption of cloud computing, at least to this point in time, does not seem to have been influenced by any other factors. ${ }^{9}$ Therefore, we cannot apply proposition 2. To mitigate these limitations, in our next section, we are going to apply the proposed methodology on the adoption of Enterprise Resource Planning (ERP) systems. ERP is a mature technology and its adoption coincided with a market bubble and a technological threat.

\footnotetext{
${ }^{9}$ The rise of data analytics, big data, and the internet of things may change this.
} 


\begin{tabular}{|c|c|c|c|c|}
\hline Years & Adopters & $\begin{array}{c}\text { Cumulative } \\
\text { Adoption }\end{array}$ & $\begin{array}{c}\text { Competitive } \\
\text { Implications }\end{array}$ & $\begin{array}{c}\text { Expected } \\
\text { Duration }\end{array}$ \\
\hline $2006-2011$ & Innovators & $2.5 \%$ & Competitive advantage & $\sim 15$ years \\
\hline $2011-2016$ & Early adopters & $16 \%$ & Competitive advantage & $\sim 10$ years \\
\hline $2016-2021$ & Early majority & $50 \%$ & Competitive advantage & $\sim 5$ years \\
\hline $2021-2026$ & Late majority & $84 \%$ & Parity & NA \\
\hline $2026-2031$ & Laggards & $100 \%$ & Parity & NA \\
\hline
\end{tabular}

\section{Table 1: Cloud Computing Predictions}

\subsection{Historical Evidence: Expected Duration due to ERP Adoption}

ERP systems, when successfully implemented, can link all primary and support activities within a firm (i.e., manufacturing, logistics, sales, procurement, finance, human resources, etc.) into a comprehensive and integrated system that is based on a shared database. In other words, an ERP can work as the conduit that connects all primary and support activities within the company' value chain, and integrate its supply chain. The expected benefits typically include reduction in working capital, and access to more accurate information faster about suppliers, customers, and employees. Firms that can leverage this information to support their business strategy are bound to reap significant benefits from their investment. However, the investment in an ERP system is the largest, most demanding and complex IS implementation that the firm will undertake. As a result the risk of failure during implementation has been very high. In some cases the results can be catastrophic. It has been argued that the 1996 bungled ERP implementation of FoxMeyer contributed to the firm's bankruptcy.

The earlier version of ERP systems trace their roots in material requirements planning (MRP) systems, which have been around for several decades. However, the modern manifestation of ERP systems has been associated with SAP and more specifically the release of SAP R/3 in 1992. Assigning the commencement of ERP systems to the early nineties is consistent with evidence from ERP studies that report announcements of ERP adopting firms (e.g., Nicolaou et al. 2003; Hendricks et al. 2007). Therefore, it stands to reason that we can assign the early nineties (1991-1992) as the commencement of ERP systems. 
Adoption rate was relatively slow in the early 1990s, but it took off during the second half when firms realized that the $\mathrm{Y} 2 \mathrm{~K}$ problem was posing a threat on existing legacy systems. Many companies saw this as an opportunity to replace their legacy systems (Anderson et al. 2003). This adoption pattern has been captured in the ERP hype cycle generated by Wang (2010) in Figure 7 - left panel. The right panel of figure 7 shows the number of ERP related articles in LexisNexis from 1990-2015.
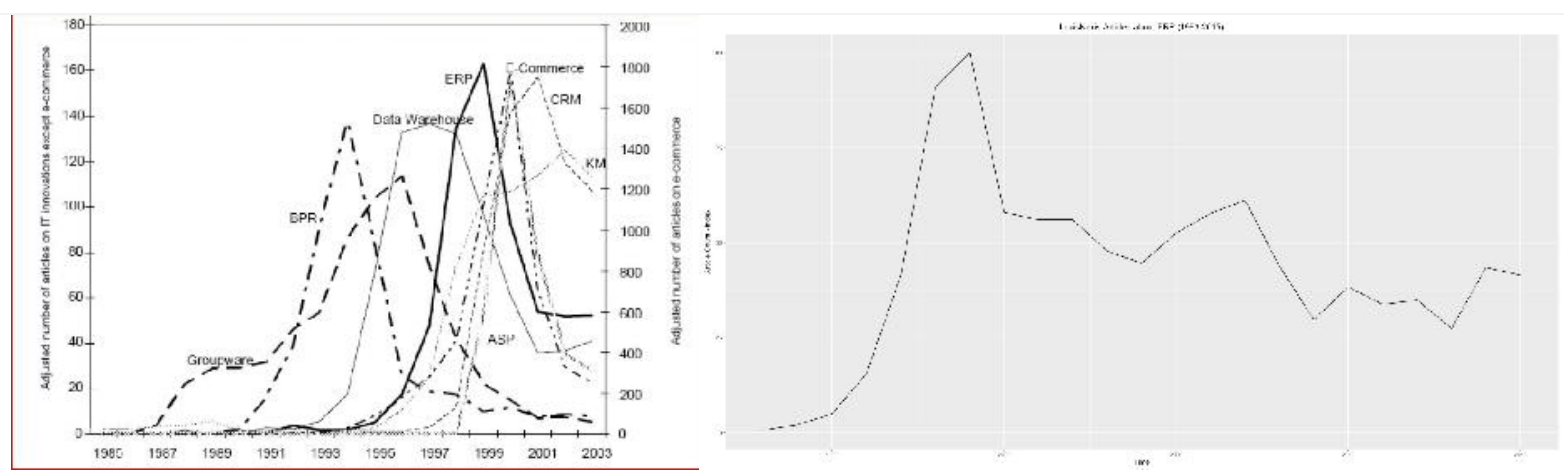

Figure 7: ERP Adoption: Wang 2010 (left)-LexisNexis (right)

If we were to ignore the pivotal role of $\mathrm{Y} 2 \mathrm{~K}$ in the adoption of ERP systems, we would have been inclined to conclude that the period from approximately 1991-1992 to 1999 reflects one standard deviation in the adoption cycle (Proposition 1a). Assuming a standard deviation of 8 years would have let us to conclude that the average adopting firm would have achieved a competitive advantage that would not have ceased till approximately 2020. However, incorporation of the Y2K effect, suggests that the late nineties mark the "take off" point of mainstream ERP adoption or entry to the plateau of productivity in the hype cycle. This means that the period from 1991-92 to 1999 marks two standard deviation in the adoption cycle. This is consistent with industry reports that raised the number of adopting firms worldwide to at least 30,000 (Mabert et al. 2001).

Therefore, assuming a standard deviation of four year and weighing the percentage of firms adopting in each of the first three adopting groups (empirical rule), we could estimate that the average duration would be around three years:

$$
0.025 * 12+0.135 * 8+0.34 * 4=2.74 \text { years }
$$


This is consistent with the three year period that has been used in empirical ERP studies (e.g., Hendricks et al. 2007; Anderson et al. 2003). ${ }^{10}$ Hendricks et al. (2007) found that firms that invested in ERP systems had higher ROA than matched portfolio that excludes ERP adopters. The study treats firms that have made announcements before 1998 as early adopters, ${ }^{11}$ and conclude that they "... may have benefited more from ERP implementation when compared to later adopters" (p. 77). Anderson et al. (2003) found strong market reaction to spending on ERP adoption.

We would like to close this discussion by reiterating our previous caveat, which is supported by several ERP studies, that the expected competitive benefits due to ERP adoption are dependent on a host of firm specific (organizational) and external factors (e.g., Nicolaou and Bhattacharya 2006; Nicolaou and Bhattacharya 2008). In other words, the prediction is for the average adopting firm.

\section{Limitations}

The problem with any attempt to generate a predictive framework is that of trying to strike a balance between detail and usefulness. The temptation in the context of this study would have been to try to incorporate additional technology and adopter specific attributes. For example, cloud computing as an emerging technology is very general. At a minimum one could consider three version of IaaS, PaaS, and SaaS and observe different adoption patterns.

Approaching the same technology from an adopters standpoint, there are numerous firm specific factors that will define the firm specific duration of a competitive advantage for each adopter. For example, the firm specific expected competitive advantage due to emerging technology adoption would depend on such factors as: the adopting firm's business strategy (product differentiator or cost leader); the role of technology in the

\footnotetext{
${ }^{10}$ The study of Tian and $\mathrm{Xu}$ (2015) uses five years but their choice is driven by standard research practice in the estimation of dependent variable rather than expectations for duration of competitive benefits of ERP adoption. They use five years to estimate standard deviation of annual earnings as a proxy for firm risk.

${ }^{11}$ Please note that the definition of early adopters used by Hendricks et al. (2007) includes both innovators and early adopters in Figure 1.
} 
firm's IT strategy (support, factory, strategic, turnaround); other investments that the firm has made in complementary to the adopting technology resources and capabilities; and, the overall organizational IT capability. Similarly, the duration will be affected by external factors such as the reaction and IT capability of its competitors. Trying to incorporate every single one of these factors is beyond the scope of our study and it would make the proposed framework unyielding as Borges' (1972) map. Nevertheless, within the scope of our study, there are two limitations that we will need to address.

\subsection{Multiple hype cycles: cryptocurrencies}

Some technologies may go through several hype cycles before they enter the slope of enlightenment and plateau of productivity (Fenn 2007). Obviously, in the case of an emerging technology that goes through multiple cycles, applying proposition 1a or 2 immediately after the first hype cycle, would generate inconsistent prediction of expected duration. In the following paragraphs, we are going to consider the example of an emerging technology that has been through multiple hype cycles.

Cryptocurrency is a form of digital currency that is not controlled by any central bank. It uses encryption techniques to regulate the issue of new units and verification of transfer of funds. Although, there are several cryptocurrencies available, Bitcoin is the most popular. Cryptocurrency as an emerging technology, was first introduced in Gartner's hype cycle in 2014, and reappeared in 2015. Both years, the cryptocurrency was placed near the end of the peak of inflated expectations, and it was coded with a dark blue dot, an indication that the technology could take between 5 to 10 years before it could reach the plateau of productivity. Given that the starting point for the new technology is approximately 2009, we could have generated the following predictions: 1 . Bitcoin has completed approximately one standard deviation in its adoption cycle. Therefore its standard deviation is approximately 5 to 6 years. 2. Based on this, we could have predicted that it would reach its plateau of productivity 2020 or 2021. 3. It would have been adopted by approximately half of the targeted population and cease producing competitive benefits by 2025 or 2026. 
However, an analysis based on Google trends, using the keywords "cryptocurrency" and "bitcoin", shows a different story. As shown in Figure 8, the search interest shows three spikes (hype cycles). The first one is approximately in the end of 2011, the second in 2013, and the most recent one in 2014. The interest in cryptocurrency seems to get stronger each time. The most recent one seems to coincide with Gartner's Hype Cycle. However, we don't know whether cryptocurrency will go from disillusionment to enlightenment and plateau of productivity or simply enter another hype cycle.

Therefore, any prediction regarding adoption and expected competitive gains should be seen in the backdrop of these limitations. Last but not least, any prediction about bitcoin are likely to be influenced or influence the adoption of another technology, i.e., blockchain. A possible extension of our methodology would be to consider clusters of technologies which are likely to influence each other.

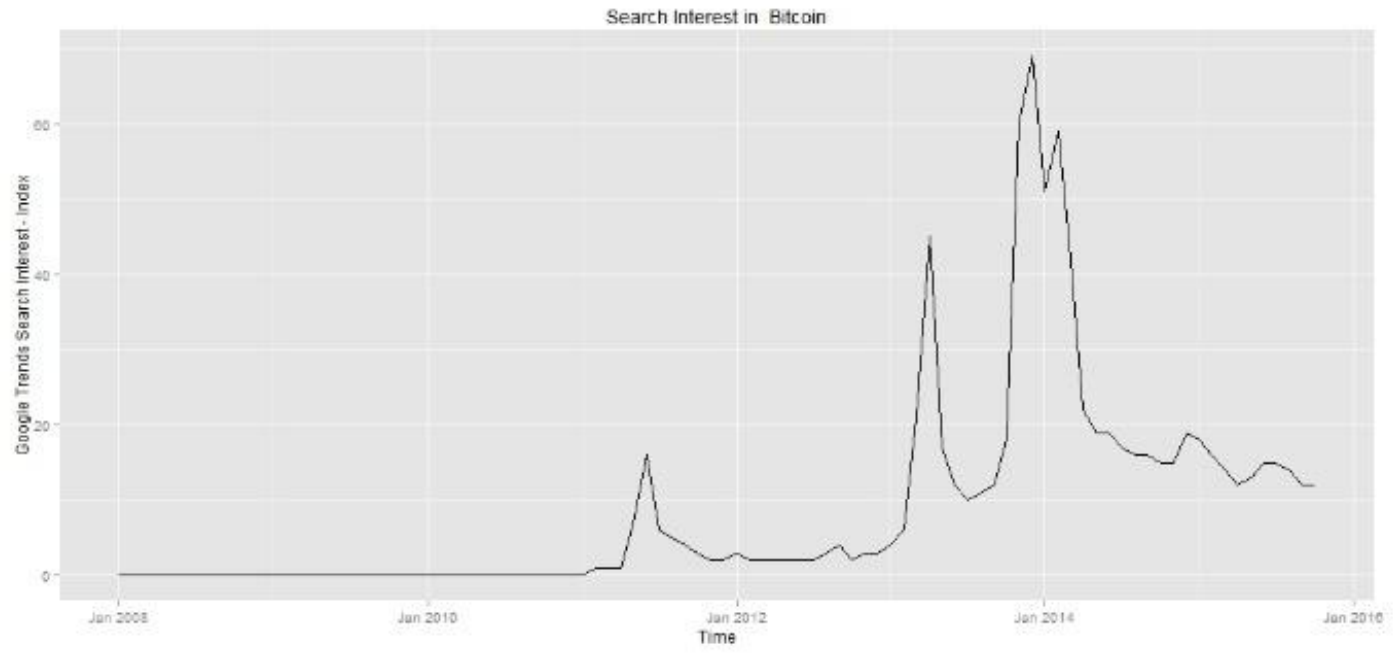

Figure 8: Google Trends - cryptocurrency

\subsection{Commencement of emerging technology}

Theoretically, the normal distribution has no limits. This means that the selection of the starting point in the context of an adoption cycle is critical and its selection can lead to erroneous results. For example, the peak of expectations for customer relationship management (CRM) systems came in the late 1990s. However, the selection of a starting point would depend on our definition of CRMs. If we were to associate the development 
of loyalty cards, i.e., the attempt to create a database for the systematic capture of customer related information, as the manifestation of a CRM then the origin should be traced back to 1981 when American Airlines introduced its loyalty card (Fenn and Raskino 2008). This would mean that one standard deviation would be close to 20 years. Thus firms that had implemented a CRM in 1999, would have expected their competitive advantage to last another forty years!

On the other hand, if we were to focus on the development of the CRM as a technology itself, the starting point could have been in the early 1990s. Thus indicating a standard deviation of 10 years, and the advantage for firms investing in 1990 would have expected to last for another twenty years. Finally, one last piece of information should be added into this puzzle. The peak of expectations for CRM, coincided with the internet hype and the introduction of SalesForce.com, which made possible the adoption of CRM as a service. Thus, the 1999 should be treated as a take-off point (entry to the plateau of productivity) for CRM, which means that from the early 1990s to the 1999, we have two standard deviations. Therefore, a firm that had adopted a CRM in 1999 should have expected to see its competitive advantage evaporate by the mid-2000s. The last prediction is more realistic and consistent with an observation that loyalty cards had lost their appeal by the mid-2000s (Fenn and Raskino 2008).

\section{Concluding Remarks}

The study proposed a synthesis of two major and distinct streams of literature (technology diffusion and resource based view) in order to develop a framework for generating predictions related to the expected duration of a competitive advantage due to adoption of an emerging technology. One of the main advantages and contribution of this study is the fact that resulting propositions are relatively easy to implement. Researchers and professional who want to explore the implications of our propositions in the context of a new technology can do this using readily available tools such as the Google Trends. The caveat emptor is that this simplicity has its limitations, therefore, researchers and professional should use their domain specific knowledge to supplement these predictions. 
As a final thought, and as a reminded of the tradeoffs of all studies like this one, we should keep in mind Borges' (1972) message from his essay "On Exactitude of Science “. . . In that Empire, the Art of Cartography attained such Perfection that ... the

Cartographers Guilds struck a Map of the Empire whose size was that of the Empire, and which coincided point for point with it. The following Generations, who were not so fond of the Study of Cartography as their Forebears had been, saw that that vast map was Useless,. "12

${ }^{12}$ The quote is form the Wikipedia. 


\section{References}

Abrahamson, E. 1991. Managerial Fads and Fashions: The Diffusion and Rejection of Innovations. The Academy of Management Review 16 (3): 586-612.

Abrahamson, E., and L. Rosenkopf. 1993. Institutional and Competitive Bandwagons: Using Mathematical Modeling as a Tool to Explore Innovation Diffusion. The Academy of Management Review 18 (3): 487-517.

Amit, R., and P. Schoemaker. 1993. Strategic assets and organizational rent. Strategic Management Journal 14 (1): 33-46.

Anderson, M. C., R. D. Banker, and S. Ravindran. 2003. The new productivity paradox. Communications of the ACM 46 (3): 91-94.

Barney, J. 1991. Firm Resources and Sustained Competitive Advantage. Journal of Management 17 (1): 99-120.

Barney, J. B. 2002. Gaining and Sustaining Competitive Advantage. 2nd ed. Upper Saddle River, NJ: Prentice Hall.

Borges, J. L. 1972. A universal history of infamy. 1st ed. New York: EPDutton.

Cyert, R. M., and J. G. March. 1992. A behavioral theory of the firm. 2nd ed. Cambridge, Mass: Wiley-Blackwell.

Dehning, B., and T. C. Stratopoulos. 2003. Determinants of a sustainable competitive advantage due to an IT-enabled strategy. Journal of Strategic Information Systems 12 (1): 7-28.

Dierickx, I., and K. Cool. 1989. Asset stock accumulation and sustainability of competitive advantage. Management Science 35 (12): 1504-1511.

DiMaggio, P. J., and W. W. Powell. 1983. The Iron Cage Revisited: Institutional Isomorphism and Collective Rationality in Organizational Fields. American Sociological Review 48 (2): 147-160.

Fenn, J. 2007. Understanding Gartner's Hype Cycles, 2007. Research.

Fenn, J., and M. Raskino. 2008. Mastering the Hype Cycle: How to Choose the Right Innovation at the Right Time. Harvard Business Press.

Gartner. n.d. Hype Cycle. Gartner Research Methodologies. http://www.gartner.com/technology/research/methodologies/hype-cycle.jsp.

Hendricks, K. B., V. R. Singhal, and J. K. Stratman. 2007. The impact of enterprise systems on corporate performance: A study of ERP, SCM, and CRM system implementations. Journal of Operations Management 25 (1): 65-82.

Hof, R. D. 2006. Jeff Bezos' Risky Bet. BloombergView. http://www.bloomberg.com/bw/stories/2006-11-12/jeff-bezos-risky-bet.

Lim, J.-H., T. C. Stratopoulos, and T. Wirjanto. 2011. Path Dependence of Dynamic Information Technology Capability: An Empirical Investigation. Journal of Management Information Systems 28 (3): 45-84.

Mabert, V. A., A. Soni, and M. A. Venkataramanan. 2001. Enterprise resource planning: common myths versus evolving reality. Business Horizons 44 (3): 69-76.

Mata, F., W. Fuerst, and J. Barney. 1995. Information technology and sustained competitive advantage: A resource-based analysis. MIS Quarterly 14 (4): 487505. 
Meyer, J. W., and B. Rowan. 1977. Institutionalized Organizations: Formal Structure as Myth and Ceremony. American Journal of Sociology 83 (2): 340-363.

Nicolaou, A., and S. Bhattacharya. 2008. Sustainability of ERPS performance outcomes: The role of post-implementation review quality. International Journal of Accounting Information Systems 9 (1): 43-60.

Nicolaou, A. I., and S. Bhattacharya. 2006. Organizational performance effects of ERP systems usage: The impact of post-implementation changes. International Journal of Accounting Information Systems 7 (1): 18-35.

Nicolaou, A. I., T. C. Stratopoulos, and B. Dehning. 2003. Financial analysis of potential benefits from ERP systems adoption. Journal of Business and Information Technology 2 (1): 40-50.

Penrose, E. T. 1995. The theory of the growth of the firm. 3rd ed.. Oxford ; New York: Oxford University Press.

Rogers, E. M. 1995. Diffusion of Innovations. Fourth. New York, NY: Simon and Schuster.

Stratopoulos, T. C., and J.-H. Lim. 2010. IT innovation persistence: an oxymoron? Communications of the ACM 53 (5): 142-146.

Swanson, E. B., and N. C. Ramiller. 2004. Innovating mindfully with information technology. MIS Quarterly 28 (4): 553-583.

Tian, F., and S. X. Xu. 2015. How Do Enterprise Resource Planning Systems Affect Firm Risk? Post-Implementation Impact. Management Information Systems Quarterly 39 (1): 39-60.

Wang, P. 2010. Chasing the Hottest IT: Effects of Information Technology Fashion on Organizations. MIS Quarterly 34 (1): 63-85.

Wernerfelt, B. 1984. A resource-based view of the firm. Strategic Management Journal 5 (2): $171-180$.

Zhu, K. 2004. The Complementarity of Information Technology Infrastructure and ECommerce Capability: A Resource-Based Assessment of Their Business Value. Journal of Management Information Systems 21 (1): 167-202. 